\title{
THE MEDIATING EFFECT OF FUTURE EXPECTATIONS ON THE RELATIONSHIP BETWEEN NEIGHBORHOOD CONTEXT AND ADOLESCENT BULLYING PERPETRATION
}

\author{
Carissa J. Schmidt \\ University of Michigan \\ Jennifer Pierce \\ Wayne State University \\ Sarah A. Stoddard \\ University of Michigan
}

Bullying is an important public health issue among adolescents. Few studies have examined how neighborhood context affects adolescent bullying. The purpose of this study was to examine the relationship between neighborhood collective efficacy and bullying perpetration and sought to determine whether future expectations mediated this relationship. A sample of 1967 th-grade students (60\% female; $27 \%$ White) from a Midwestern school completed measures assessing past 30-day bullying perpetration, neighborhood collective efficacy, and future expectations. The effect of neighborhood collective efficacy on bullying was fully mediated by future expectations. Our findings suggest that neighborhood collective efficacy is associated with lower bullying perpetration by increasing adolescents' expectations for the future. Strong social relationships increase adolescents' perceptions of a positive future. Youth with more positive expectations of the

This research was supported by an award from the University of Michigan Injury Center (PI: Stoddard). Sarah Stoddard is supported by a Mentored Scientist Career Development Award (1K01 DA 034765) from the National Institute of Drug Abuse and Jennifer Pierce was supported by an internship award from The University of Michigan Injury Center (Centers for Disease Control and Prevention, U49 CE002099).

We owe a special thanks to students who participated in this project as well as the school administration for making this study possible.

Please address correspondence to: Carissa Schmidt, Health Behavior and Health Education, University of Michigan School of Public Health, 1415 Washington Heights, Ann Arbor, MI 48109. E-mail: carissaj@umich.edu 
future may be less likely to participate in bullying if they perceive the possible outcomes of bullying to be negative and an impediment to goals.

(C) 2016 Wiley Periodicals, Inc.

Bullying has received heightened attention in recent years and has proven to be a substantial public health issue. Aggressive behavior has been conceptualized as a spectrum of intentional actions, with bullying included as a minor form that often developmentally precedes more serious and damaging behavior (e.g., violent delinquency; Espelage, Bosworth, \& Simon, 2001; Loeber \& Hay, 1997). Bullying is repeated and intentional behavior (Olweus, 1993; Gladden, Vivolo-Kantor, Hamburger, \& Lumpkin, 2013) and is characterized as one person (i.e., the victim) having less power than another (i.e., the bully; Olweus, 1993). Relational bullying is defined as actions that are more covert and psychologically manipulative (Crick, Ostrov, \& Werner, 2006) such as spreading rumors or gossiping, excluding others on purpose, and encouraging others to dislike someone (Lagerspetz, Björkqvist, \& Peltonen, 1988). Alternatively, physical bullying includes more overt, physical forms of aggression (e.g., threatening someone, hitting or hurting another person, or ruining someone's possessions). Despite these distinctions, both forms of bullying are associated with negative outcomes (Juvonen, Graham, \& Schuster, 2003; Nansel et al., 2001; Wolke, Woods, Bloomfield, \& Karstadt, 2001).

Unfortunately, previous research has demonstrated that bullying behaviors are incredibly common during adolescence. In one nationally representative sample of 6 ththrough 10th-grade students, approximately $30 \%$ of participants reported moderate or frequent bullying behavior as the bully $(13 \%)$, victim $(11 \%)$, or both $(6 \%$; Nansel et al., $2001)$. In a more recent national study of 6 th- through 10 th-grade students, $21 \%$ of students were involved in physical bullying and $54 \%$ were involved in relational bullying as either a perpetrator or victim (Wang, Iannotti, \& Nansel, 2009).

Previous research indicates numerous associations between bullying perpetration and other negative social, psychological, and behavioral outcomes (Juvonen et al., 2003; Loeber \& Hay, 1997; Nansel et al., 2001; Wolke et al., 2001). For example, physical bullying during adolescence has been linked to later violent behavior, including assault, rape, and robbery (Loeber, 1996), and fewer prosocial behaviors later in life (Juvonen et al., 2003; Nansel et al., 2001; Wolke et al., 2001). The perpetration of relational bullying behaviors has been linked to social maladjustment, externalizing behavior, and other poor physical and behavioral outcomes (Crick, 1996; Galen \& Underwood, 1997; Williams, Fredland, Han, Campbell, \& Kub, 2009). Given the prevalence and severity of the consequences of physical and relational bullying, it is imperative to focus on understanding factors that may prevent bullying among youth.

From an ecological perspective (Bronfenbrenner, 1979), factors at multiple levels (e.g., individual, family, school, community, societal) contribute to youth behaviors, including bullying. Although bullying most commonly takes place in school settings (Bradshaw, Sawyer, \& O'Brennan, 2007), the school is embedded within the neighborhood context and neighborhood factors can influence the school environment (Bronfenbrenner, 1979; Smrekar \& Bentley, 2011; Willits, Broidy, \& Denman, 2013). Furthermore, children spend much of their time in schools (Merrell, Gueldner, Ross, \& Isava, 2008). As a result, neighborhood factors that influence children directly will be enacted in the school setting. Therefore, neighborhood context can play a significant role in perpetuating bullying behavior in schools. 
There are risk and protective factors present at all levels of Bronfenbrenner's (1979) ecological model. Risk factors are those that increase the likelihood of negative outcomes occurring, whereas protective factors are those that decrease the likelihood of negative outcomes (Gendron, Williams, \& Guerra, 2011; Hemphill et al., 2012; Kokkinos \& Kipritsi, 2011; Stassen, 2007). Previous research has identified potential risk factors for perpetration. For example, youth growing up with persistent parental anger, youth who experience developmental, emotional, or behavioral problems, and youth who have mothers with mental health problems are at greater risk for bullying perpetration (Shetgiri, Lin, \& Flores, 2013).

The examination of protective factors has been less common. Several experts in resilience research have emphasized the importance of giving more attention to enhancing positive factors in the lives of youth rather than focusing only on eliminating risk (Jessor, Van Den Bos, Vanderryn, Costa, \& Turbin, 1995; Masten, Cutuli, Herbers, \& Reed, 2002). Therefore, researchers have begun to identify factors that reduce the likelihood of engaging in bullying behaviors. For example, at the individual level, being older (Nansel et al., 2001; Shetgiri et al., 2013) and using problem-focused coping strategies (Khamis, 2014) have been associated with less bullying perpetration.

Family-level factors such as maternal warmth (Bowes et al., 2009), parental involvement (Flouri \& Buchanan, 2003), emotional support from parents (Wang et al., 2009; Zimmerman, Glew, Christakis, \& Katon, 2005), and growing up in a two-parent family (Kim, Koh, \& Leventhal, 2004) have also been identified as protective factors. Additionally, school-level factors such as smaller school size (Bowes et al., 2009) and positive class climate (Stefanek, Strohmeier, van de Schoot, \& Spiel, 2011) are associated with less bullying behavior. Neighborhood factors such as neighborhood resources and neighborhood cohesion have been linked to less aggressive behavior (Caughy et al., 2012; Molnar, Cerda, Roberts, \& Buka, 2008; Sampson, 2006).

The present study extends this work by examining the potential of future expectations and neighborhood collective efficacy (i.e., the cohesion and informal social control within a neighborhood) as factors that inhibit bullying perpetration.

\section{Future Expectations and Bullying}

One individual-level factor that may help youth avoid engaging in aggressive or bullying behavior is a positive expectation of the future. Future orientation has been described as an individual's thoughts, plans, motivations, hopes, and feelings about his or her future (Arnett, 2000; Nurmi, 1989a, 1991; Nuttin, 1964; Trommsdorff, 1983). Having positive future expectations is associated with positive development among youth (Nurmi, 1993). Future expectations provide youth with motivation for reaching future-oriented goals and play an important role in adolescents' decision making (Trommsdorff, Lamm, \& Schmidt, 1979). Youth who have well-articulated goals and believe they can attain these goals are more likely to be aware of the consequences of engaging in certain negative and risk behaviors (Routledge \& Arndt, 2005). Conceptually, youth who have positive future expectations may avoid bullying in an effort to reach their goals.

Limited research has been conducted examining the relationship between future expectations and bullying behavior. A recent study showed a direct and indirect effect of future expectations on youth physical and relational bullying behavior (Stoddard, Schmidt, Saulson, \& Zimmerman, 2013). More specifically, future expectations were associated with less relational bullying for males and females and with less physical bullying for females (Stoddard et al., 2013). There is also evidence supporting a link between 
future expectations and other youth problem behaviors such as violence and aggression. For example, in a recent examination of the relationship between future expectations and violent behavior, Stoddard, Zimmerman, and Bauermeister (2011) found that higher levels of future orientation were related to less violent behavior over time. Furthermore, these results supported the findings of Birnbaum et al. (2003), in which positive school functioning was related to fewer violent behaviors in middle school youth with positive future expectations.

\section{Neighborhood Context and Bullying Behavior}

Few studies have examined the relationship between neighborhood context and youth bullying perpetration. Espelage and colleagues (2000) found that adolescents who perceived their neighborhood as unsafe were more likely to perpetrate bullying in school compared to adolescents with fewer perceived neighborhood safety concerns. Additionally, children whose mothers reported having problems with neighbors (e.g., arguments with neighbors, noisy neighbors, and loud parties at neighbors' houses) were more likely to be involved in bullying at school (Bowes et al., 2009).

Although less is known specifically about the relationship between neighborhood context and bullying behavior, several studies have linked characteristics of neighborhoods to the broader spectrum of youth aggression. For example, Jennings, Maldonado-Molina, Reingle, and Komro (2011) found that neighborhood problems including violence, drug and substance use/abuse, and lack of police supervision significantly predicted physical aggression within a sample of urban youth even after accounting for individual level risk factors. Likewise, Vanfossen, Hendricks-Brown, Kellam, Sokoloff, and Doering (2010) found that neighborhood violence, employment, income, and percentages of single male and female-headed households influenced the development of aggressive behavior in a sample of urban youth.

Researchers examining bullying and aggressive behaviors from a socioecological perspective have found that higher levels of neighborhood poverty were associated with more physical aggression (Reiss \& Roth, 1993; Shaw \& McKay, 1942). However, Romano, Tremblay, Boulerice, and Swisher (2005) found a negative relationship between neighborhood poverty and physical aggression. Differences in the literature may be explained by other factors influencing the relationship between neighborhood context and aggression (e.g., family conflict; Karriker-Jaffe, Foshee, Ennett, \& Suchindran, 2013). Regardless of discrepancies in the literature, much of the literature examining the relationship between neighborhood context and aggressive behaviors has focused predominantly on neighborhood risk factors.

With an increased interest in understanding factors that promote positive development, researchers have begun to examine the relationship between positive characteristics of neighborhoods and bullying and aggressive behaviors. Lenzi et al. (2012) found that adolescents who perceived greater opportunities in their neighborhood were more likely to demonstrate prosocial competence. Positive neighborhood characteristics may influence outcomes through various factors, including provision of resources, opportunities, limit setting, demonstration of prosocial behavior, and development of positive interpersonal skills (Lenzi et al., 2012; Vanfossen et al., 2010).

Findings specific to bullying and aggression have been equivocal. Neighborhood resources and collective efficacy, or the cohesion and informal social control within a neighborhood (Sampson \& Raudenbush, 1999), have been associated with less aggressive and delinquent behaviors among urban youth (Caughy et al., 2012; Molnar et al., 
2008; Sampson, 2006). However, Odgers and colleagues (2009) found the relationship between neighborhood collective efficacy and aggressive and other antisocial behaviors were present only among youth living in deprived neighborhoods. Conversely, Herrenkohl and colleagues (2003) found that social cohesion within a neighborhood was not a protective factor against violence at 18 years of age for youth who were aggressive at age 10 . Contradictions within the literature warrant further investigation.

More importantly, although several studies have provided evidence of a relationship between neighborhood context and youth aggression, very few studies have investigated the mechanism through which these positive neighborhood factors influence aggression or, more specifically, physical and relational bullying behaviors. In the present study, we examine future expectations as one potential mechanism.

\section{Neighborhood Context and Future Expectations}

It has been well established that neighborhood context often plays an indirect role in youth outcomes. Leventhal and Brooks-Gunn (2000) have demonstrated that neighborhood effects are usually mediated by more proximal factors. For example, using neighborhood models originally outlined by Jencks and Mayer (1990), Leventhal and Brooks-Gunn (2000) have proposed a norms/collective efficacy model to explain one possible pathway through which neighborhood context may influence youth outcomes. This model posits that neighborhood structure (e.g., low socioeconomic status, residential instability) influences the level of formal and informal social control within a community, and this community-level control accounts for the neighborhood effects. However, this model opens the door to the possibility that community-level norms and collective efficacy may further be mediated by individual-level psychological processes.

Bronfenbrenner (1979) stresses the importance of considering relationships between levels when investigating youth outcomes. Therefore, the effect of neighborhood level factors on bullying perpetration may work through individual level factors. For example, DuRant, Cadenhead, Pendergrast, Slavens, and Linder (1994) found that youth who had experienced neighborhood violence also reported feelings of depression, hopelessness, and a decreased sense of purpose. Furthermore, Stoddard, McMorris, and Sieving (2011) found that hopefulness was associated with lower levels of youth aggression. Considering these findings, it is plausible that neighborhood context influences youths' sense of hope for the future, which further influences youth aggression.

Similarly, it is possible that neighborhood factors such as collective efficacy may influence individual factors such as future expectations. In fact, Jose, Ryan, and Pryor (2012) found that a higher level of community connectedness was associated with adolescent well-being, including future orientation. In neighborhoods where adults get along with each other, work together for the good of their community, and act as role models for youth, it is possible that youth in the community are more likely to have higher future expectations for themselves. Social learning theory (Bandura, 1977) posits that individuals learn behaviors through observing other people whom they look up to. Therefore, in neighborhoods with high perceived collective efficacy, adolescents may be more likely to observe collaborative behavior among adults in their neighborhood, to look up to these adults, and to realize they too can demonstrate positive behaviors in the future.

\section{Present Study}

This study examines the relationship between neighborhood collective efficacy and engaging in bullying behaviors within a sample of 7 th-grade students residing in a 
low-income suburban area and sought to determine whether future expectations mediate this relationship. To the best of our knowledge, this is the first study to examine the relationship between neighborhood collective efficacy, future expectations, and perpetration of bullying behaviors among youth, and the potential of future expectations as a mediator between neighborhood collective efficacy and youth bullying behavior. Previous research suggests negative neighborhood characteristics are related to adolescent bullying (Bowes et al., 2009; Espelage et al., 2000). Yet positive neighborhoods provide a context for youth to develop positive future expectations by observing adult role models in the neighborhood (Bandura, 1977).

Furthermore, positive future expectations have been associated with less physical and relational bullying (Stoddard et al., 2013). Although neighborhood effects are often mediated by other factors (Leventhal \& Brooks-Gunn, 2000), there is a lack of research examining future expectations as a possible explanation for how (or the mechanism through which) neighborhood context influences youth outcomes, such as bullying perpetration. Based on previous research, we hypothesize that adolescents who live in more supportive neighborhoods will report fewer bullying behaviors. In addition, we hypothesize that future expectations will be related to fewer bullying behaviors. Finally, we hypothesize that future expectations will mediate the relationship between neighborhood collective efficacy and bullying.

\section{METHOD}

\section{Sample}

This study is based on data collected as part of a school-based survey focused on understanding risk and protective factors for youth violence and bullying. Data were collected from 7th-grade students at one Midwestern U.S. middle school during their health class. All 7th-grade students at this school were invited to participate. Of approximately 400 7 th-grade students invited, $49 \%\left(n=196\right.$; mean $[M]_{\text {age }}=12.39$, standard deviation $[S D]$ $=0.52 ; 60 \%$ female) chose to participate. The sample was ethnically diverse: $45 \%$ African American, 27\% White, $21 \%$ multiracial, and $7 \%$ other. Only participants who completed at least $50 \%$ of the scale items for each measure were included in the analyses.

Thus, the final sample size was 176 adolescents $\left(M_{\text {age }}=12.87, S D=0.50 ; 63 \%\right.$ female). Table 1 summarizes the descriptive characteristics for the final sample. Attrition analyses were conducted to determine if the 20 participants excluded from this study were significantly different compared to the 176 participants included in the study. Results of the attrition analyses determined that these individuals did not differ significantly in age, $t(194)=0.90, p=.37$; gender, $\chi^{2}(1, \mathrm{~N}=194)=0.88, p=.35$; or race, $\chi^{2}(5, \mathrm{~N}=$ 193) $=7.97, p=.16$.

\section{Procedures}

This study was approved by the University of Michigan Institutional Review Board. A Certificate of Confidentiality was obtained from the National Institutes of Health. Both written parental consent and student assent were obtained prior to participation. Participation in the study was completely voluntary; no compensation was provided to participants.

Trained research staff administered the survey during health class in the 2011-2012 academic year. The survey included a number of measures assessing known risk and protective factors associated with youth violence and bullying and was completed in about 
Table 1. Descriptive Statistics for Study Variables $(N=176)$

\begin{tabular}{lccc}
\hline Variable & $N(\%)$ & $M(S D)$ & Range \\
\hline Race & & & - \\
$\quad$ White & $46(28.40)$ & - & - \\
$\quad$ African American & $75(46.30)$ & - & - \\
$\quad$ Mixed/other & $41(25.30)$ & - & - \\
Sex & $60(37.00)$ & - & - \\
$\quad$ Male & $102(63.00)$ & $12.86(0.48)$ & $12.01-14.34$ \\
Female & - & $6.02(1.97)$ & $1.00-7.00$ \\
Age & - & $3.12(0.70)$ & $1.00-4.00$ \\
SES & - & $3.59(0.43)$ & $1.50-4.00$ \\
Neighborhood collective efficacy & - & $8.70(9.90)$ & $0.00-52.00$ \\
Future expectations & - & - & \\
Bullying & & & \\
\hline
\end{tabular}

Note. $\mathrm{SD}=$ standard deviation; $\mathrm{SES}=$ socioeconomic status.

45 minutes. Students who did not have parental consent or did not provide assent were given worksheets to complete during the testing period. For students with lower reading levels or limited English proficiency $(n=4)$, the survey was read aloud privately in a separate room.

\section{Measures}

Neighborhood collective efficacy. Neighborhood collective efficacy was assessed with eight items adapted from Sampson and Raudenbush's (1999) Neighborhood Collective Efficacy scale (e.g., "People in my neighborhood are willing to help their neighbors," "I live in a neighborhood where people know and like each other," and "There are adults in my neighborhood that I can look up to"). Response options ranged from 1 (disagree a lot) to 4 (agree a lot). A mean composite score was computed for each participant with higher scores indicating a higher level of collective efficacy within their neighborhood $(\alpha=.90)$.

Future expectations. Six items were used to assess participants' level of future expectations (e.g., "I will be able to handle the problems that might come up in my life," "I will be able to handle my school work," and "I will have a happy life"; Wyman, Cowen, Work, \& Kerley, 1993). Response options for each statement ranged from 1 (disagree a lot) to 4 (agree a lot). A mean composite score was computed for each participant with higher scores indicating a greater level of positive future expectations $(\alpha=.76)$.

Bullying behavior. Consistent with other researchers (Espelage et al., 2000), our measure focused specifically on aggressive behaviors that characterize bullying. We adapted twelve items from the aggression subscale of the Problem Behavior Frequency Scale to assess participants' bullying behavior (Farrell, Danish, \& Howard, 1992a; Multisite Violence Prevention Project [MVPP], 2004). Students indicated how often they had engaged in the following behaviors in the past month: leave someone out on purpose; pick on someone; say things about another student to make others laugh; ignore or stop talking to someone; spread rumors or gossip about someone; make fun of someone's family; threaten not to be someone's friend; threaten to hit or hurt another student; ask someone to fight; say something hurtful to someone in email or on the internet; ruin someone's stuff; and been in a physical fight. Response options for each item ranged from 0 (never) to 5 
( 5 times or more). We computed a sum composite score with higher scores indicating more bullying behavior $(\alpha=.88)$. This scale incorporated aspects of relational, nonphysical, and physical bullying and aggression.

Demographic characteristics. Participants were asked to report their gender (male $=0$; female $=1$ ) and their race/ethnicity. For analysis, race was dummy-coded into three variables: African American $(0=n o, 1=y e s)$, White $(0=n o, 1=y e s)$, and mixed/other $(0=n o, 1=y e s)$. As a marker of socioeconomic status, participants were asked to report their mother's educational attainment. Response options included: 8th grade or less; some high school; completed high school or GED; vocational or training school; some college; completed college; graduated or professional school after college; no contact with mother; and don't know. Mother's educational attainment was imputed for students with missing data, who reported no contact with their mother or didn't know their mother's educational attainment. We used Cohen, Cohen, West, and Aiken's (2003) method for imputation in which these individuals were assigned the mean for mother's educational attainment.

\section{Data Analytic Strategy}

Pearson's bivariate correlations were assessed to determine associations between study variables. Multivariate regression analyses were used to examine whether neighborhood collective efficacy and future expectations were associated with bullying. We used Baron and Kenny's (1986) approach to test whether the relationship between neighborhood collective efficacy and bullying was mediated by future expectations.

Using Baron and Kenny's (1986) approach, four criteria were considered for evidence of mediation: (a) the predictor (neighborhood collective efficacy) was required to be significantly associated with the hypothesized mediator (future expectations; path a); (b) the mediator (future expectations) was required to be significantly associated with the dependent variable (bullying; path b); (c) the predictor (neighborhood collective efficacy) was required to be significantly associated with the dependent variable (bullying; path c); and (d) the relationship between the predictor (neighborhood collective efficacy) and the dependent variable (bullying) must be less after controlling for the mediator (future expectations; path c'). These pathways were assessed using bivariate correlations.

A hierarchical linear regression approach was used to test for mediation effects (Baron $\&$ Kenny, 1986). The first multivariate regression model (Model 2) included neighborhood collective efficacy and demographic covariates (i.e., mother's education, gender and race/ethnicity) as predictors of bullying. Next, a multivariate regression model was estimated that contained neighborhood collective efficacy, future expectations, and demographic covariates as predictors of bullying (Model 3). All models were estimated using Stata 12.0 statistical software (StataCorp LP, 2011, College Station, TX). The Sobel test (Sobel, 1982) was obtained through the "sgmediation" command in Stata 12.0 and was used to confirm mediation. In addition, mediated effects were also tested by computing 95\% bias-corrected confidence intervals for indirect effects using bootstrapping in Stata 12.0 . 
Table 2. Bivariate Correlations Between Study Variables $(N=176)$

\begin{tabular}{lccccc}
\hline & Bullying & $\begin{array}{c}\text { Neighborhood collective } \\
\text { efficacy }\end{array}$ & $\begin{array}{c}\text { Future } \\
\text { expectations }\end{array}$ & Age & SES \\
\hline Bullying & - & & & & \\
Neighborhood collective efficacy & $-0.17^{*}$ & - & - & \\
Future expectations & $-0.31^{* *}$ & $0.40^{* *}$ & -0.07 & - & \\
Age & 0.04 & -0.02 & -0.03 & -0.03 & - \\
SES & 0.11 & 0.11 & &
\end{tabular}

Note. $\mathrm{SES}=$ socioeconomic status.

$* p<.05 . * * p<.001$.

\section{RESULTS}

\section{Descriptive Statistics}

Table 1 provides descriptive data for all study variables. The mean score for neighborhood collective efficacy was $3.11(n=176, S D=0.74)$, indicating moderate neighborhood collective efficacy. The overall mean future expectations score was $3.60(n=176, S D=0.43)$, indicating moderately high future expectations. About $76 \%(n=134)$ of participants reported repeated acts of bullying behavior.

\section{Bivariate Associations}

Correlations between neighborhood collective efficacy, future expectations, and bullying behavior were examined (refer to Table 2). We found that neighborhood collective efficacy was significantly, positively associated with future expectations $(r=.40, p<.001)$. Neighborhood collective efficacy and future expectations were significantly and negatively correlated with bullying behaviors $(r=-.17, p<.05$ and $r=-.31, p<.001$, respectively). Given the significant correlations between the three variables, the conditions necessary to assess for mediation (Baron \& Kenny, 1986) were met.

\section{Multivariate Regression Models}

Results for each model are shown in Table 3. Higher levels of future expectations were associated with less bullying behavior in Model $1(b=-6.57$, standard error $[S E]=1.66, p$ $<.001)$. In Model 2, higher levels of neighborhood collective efficacy were associated with less bullying behavior after controlling for demographic variables $(b=-2.39, S E=0.98$, $p<.05)$. In Model 3, future expectations were associated with less bullying perpetration after controlling for demographic variables $(b=-5.85, S E=1.83, p<.01)$. The inclusion of future expectations in the model made the relationship between neighborhood collective efficacy and youth bullying nonsignificant $(b=-0.98, S E=1.05, p=.35)$. The change in the estimate associated with collective efficacy between Models 2 and 3 suggests mediation. The Sobel test (Sobel, 1982) and bootstrapped confidence intervals (95\%) confirmed the mediation (Sobel test $z=-2.82, p<.01 ; 95 \%$ bias-corrected confidence interval [CI] for indirect effects: $[-2.79,-0.46])$. Figure 1 displays the mediation model with standardized parameter estimates for the paths between collective efficacy, future expectations and bullying behavior. 
Table 3. Summary of Multivariate Regression Models Testing Variables Predicting Bullying Perpetration (N =176)

\begin{tabular}{|c|c|c|c|c|c|c|}
\hline \multirow[t]{2}{*}{ Variable } & \multicolumn{2}{|c|}{ Model 1} & \multicolumn{2}{|c|}{ Model 2} & \multicolumn{2}{|c|}{ Model 3} \\
\hline & $b$ & $S E$ & $b$ & $S E$ & $b$ & $S E$ \\
\hline Neighborhood collective efficacy & - & - & $-2.39^{*}$ & 0.98 & -0.98 & 1.05 \\
\hline Future expectations & $-6.57^{* *}$ & 1.66 & - & - & $-5.85^{*}$ & 1.83 \\
\hline Gender & 0.08 & 1.46 & -0.41 & 1.49 & 0.07 & 1.46 \\
\hline SES & 0.59 & 0.54 & 0.82 & 0.56 & 0.67 & 0.55 \\
\hline Black $^{\mathrm{a}}$ & 2.50 & 1.68 & 1.55 & 1.71 & 2.33 & 1.69 \\
\hline Mixed/other & -0.33 & 1.94 & -1.46 & 1.98 & -0.52 & 1.95 \\
\hline $\mathrm{R}^{2}$ & 0.11 & - & 0.06 & - & 0.11 & - \\
\hline
\end{tabular}

Note. $\mathrm{SE}=$ standard error; $\mathrm{SES}=$ socioeconomic status.

${ }^{\mathrm{a}}$ White students were the referent group.

$* p<.05 . * * p<.001$.

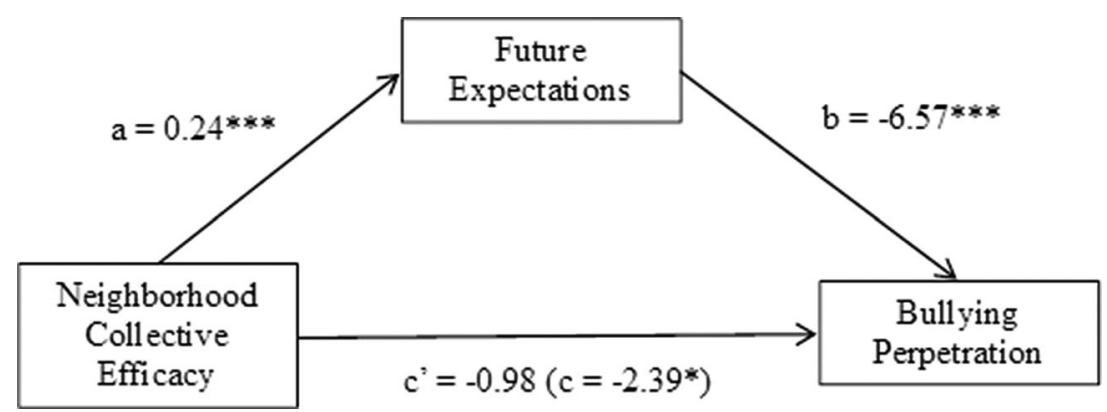

Figure 1. Mediation of neighborhood collective efficacy on bullying by future expectations. $* p<.05$. $* * p<$ $.01 . * * p<.001$.

\section{DISCUSSION}

This study investigated the relationship between neighborhood collective efficacy, future expectations, and youth bullying behavior. Our findings supported our hypotheses that more positive future expectations and higher neighborhood collective efficacy would be associated with less bullying behavior. In addition, our hypothesis that the relationship between neighborhood collective efficacy and bullying would be mediated by future expectations was supported by our findings.

Adolescents who reported a stronger sense of cohesion and support within their neighborhood reported less involvement in bullying behavior. These findings are consistent with previous research suggesting that neighborhood context can influence adolescent bullying (Bowes et al., 2009; Espelage et al., 2000). However, previous research has often considered negative neighborhood effects; thus, the present study extends prior research by providing support for positive neighborhood characteristics to influence bullying behavior.

More importantly, we found that future expectations fully mediated the relationship between neighborhood collective efficacy and bullying behavior, suggesting that neighborhood cohesion influences bullying perpetration by increasing adolescents' expectations for the future. This is consistent with the norms/collective efficacy model (Leventhal \& Brooks-Gunn, 2000), which posits that neighborhood context is often indirectly related 
to youth outcomes through individual psychosocial processes. Our findings demonstrate the importance of examining the mechanisms that explain the association between neighborhood factors and adolescent outcomes, rather than solely focusing on the main effects of neighborhood factors, and that future expectations may be an important pathway to consider.

For youth in our study, more positive future expectations were associated with less bullying behavior. Our results are consistent with other researchers who linked positive expectations for the future and hopefulness to the positive development of youth (Nurmi, 1989a,1989bb; Nurmi, Poole, \& Seginer, 1995). The relationship between positive future expectations and less perpetration of bullying behaviors may be due to a desire to achieve positive future outcomes, which may not be possible if youth perceive the consequences of bullying to be negative and a barrier to reaching goals.

Additionally, future expectations are associated with greater confidence (Snyder \& Lopez, 2005). For youth with more positive expectations for the future, relational and physical bullying may not be necessary to increase feelings of self-worth. Research suggests that humans, especially youth, desire affection and status (MacDonald, 1992; Pendell, 2002). Therefore, it is plausible that youth use bullying as a way of obtaining these desired goals (Veenstra, Lindenberg, Munniksma, \& Dijkstra, 2010). However, youth with more positive future expectations, and greater confidence, may not need to use bullying to reach these goals.

In addition, we found that neighborhood collective efficacy was highly correlated with future expectations. Youth who reported higher levels of collective efficacy also reported greater levels of positive expectations for their future. The role of collective efficacy in promoting the development of positive characteristics for youth is consistent with previous research in which greater community connectedness was associated with adolescent wellbeing, including future orientation (Jose et al., 2012). One plausible explanation for this relationship is that in neighborhoods with strong cohesion and informal social control, adults may be more likely to want the best for youth in their community and, therefore, may act as natural mentors, offering advice and guidance to youth. Having a natural mentor has been found to be positively associated with school attachment, school efficacy, and positive attitudes about school (Zimmerman, Bingenheimer, \& Notaro, 2002), all attributes that may contribute to positive future expectations for youth.

Furthermore, positive relationships with reliable, caring, and competent adults have been found to help in the development of positive future expectations among adolescents (Aronowitz, 2005; Kerpelman, Eryigit, \& Stephens, 2008; McCabe \& Barnett, 2000). Therefore, advice related to future opportunities (e.g., job opportunities and opportunities to attend college) from caring adults and natural mentors within a neighborhood may promote positive future expectations among youth.

Several study limitations should be noted. First, our sample was a convenience sample comprising 7th-grade students from one middle school within a suburban setting. Therefore, it is possible that students in this study may differ from other adolescents. As a result, our findings should not be generalized to all youth. Additional studies are needed to explore and further understand the relationship between collective efficacy, future expectations, and bullying among other populations of youth. For example, youth living in rural settings may have different perceptions of the collective efficacy within their neighborhood. Second, because of the cross-sectional design of this research study, it cannot be assumed that neighborhood collective efficacy precedes adolescents' future expectations or bullying behavior. Future research using a larger longitudinal sample of 
adolescents is warranted and may provide a better understanding of the true direction of these relationships.

Third, it is important to note that our final mediation model accounted for approximately $11.5 \%$ of variance in youths' bullying behavior. Although this is low, it is important to note that researchers focused on understanding neighborhood factors very rarely account for more than $10 \%$ of variance in youth outcomes (Duncan \& Raudenbush, 1999; Leventhal \& Brooks-Gunn, 2000); thus, our model is consistent with the variance explained by other researchers examining neighborhood effects. Fourth, it is possible that risk factors such as substance use and co-occurring delinquency might be strongly associated with neighborhood collective efficacy. Therefore, future research would benefit from teasing apart these effects.

Finally, our measure of neighborhood collective efficacy did not include items assessing collective efficacy within participants' school setting. During adolescence, youth spend a great deal of time at school (Merrell et al., 2008) and the school environment is an important component of their neighborhood. Future research that investigates these relationships using a socioecological framework (e.g., including perceived family and school-level collective efficacy measures) may help to explain greater variance in youth bullying behavior.

Despite these limitations, the current study is an important first step in understanding the role of future expectations in the relationship between neighborhood context and bullying behavior. This research offers important implications for public health interventions to help youth develop positively. Efforts to enhance neighborhood collective efficacy are incredibly important for both instilling positive future expectations in youth and in preventing bullying.

Furthermore, future bullying prevention efforts should seek to improve adolescents' perceptions of their futures. Current school bullying prevention programs have not been highly effective (Merrell et al., 2008). Although many programs have used a risk-reduction approach, Kretman, Zimmerman, Morrel-Samuels, and Hudson (2009) argue the importance of moving toward resilience-oriented youth programs as an alternative. Interventions using a resilience framework focus on enhancing promotive factors in the lives of youth. As indicated by the results of the current study, resilience-oriented bullying intervention efforts that help youth envision positive goals for their future may improve the effectiveness of the approaches currently in use.

\section{REFERENCES}

Arnett, J. J. (2000). High hopes in a grim world: Emerging adults' views of their futures and "Generation X." Youth \& Society, 31, 267-286.

Aronowitz, T. (2005). The role of "envisioning the future" in development of resilience among at-risk youth. Public Health Nursing, 22, 200-208.

Bandura, A. (1977). Social learning theory. Englewood Cliffs, NJ: Prentice Hall.

Baron, R. M., \& Kenny, D. A. (1986). The moderator-mediator variable distinction in social psychological research: Conceptual, strategic, and statistical considerations. Journal of Personality and Social Psychology, 51, 1173-1182.

Birnbaum, A. S., Lytle, L. A., Hannan, P. J., Murray, D. M., Perry, C. L, \& Forster, J. L. (2003). School functioning and violent behavior among young adolescents: A contextual analysis. Health Education Research, 18(3), 389-403. doi:10.1093/her/cyf036 
Bowes, L., Arseneault, L., Maughan, B., Taylor, A., Caspi, A., \& Moffitt, T. E. (2009). School, neighborhood, and family factors are associated with children's bullying involvement: A nationally representative longitudinal study. Journal of the American Academy of Child and Adolescence Psychiatry, 48, 545-553.

Bradshaw, C. P., Sawyer, A. L., \& O'Brennan, L. M. (2007). Bullying and peer victimization at school: Perceptual differences between students and school staff. School Psychology Review, 36(3), 361-382.

Bronfenbrenner, U. (1979). The ecology of human development: Experiments by nature and design. Cambridge, MA: Harvard University Press.

Caughy, M., Franzini, L., Windle, M., Dittus, P., Cuccaro, P., Elliott, M., \& Schuster, M. (2012). Social competence in late elementary school: Relationships to parenting and neighborhood context. Journal of Youth \& Adolescence, 41 (12), 1613-1627.

Cohen, J., Cohen, P., West, S. G., \& Aiken, L. S. (2003). Applied multiple regression/correlation analysis in the behavioral sciences (3rd ed.). Mahwah, NJ: Erlbaum.

Crick, N. R. (1996). The role of overt aggression, relational aggression, and prosocial behavior in the prediction of children's future social adjustment. Child Development, 67(5), 2317-2327.

Crick, N. R., Ostrov, J. M., \& Werner, N. E. (2006). A longitudinal study of relational aggression, physical aggression, and children's social-psychological adjustment. Journal of Abnormal Child Psychology, 34, 127-138.

Duncan, G. J., \& Raudenbush, S. W. (1999). Assessing the effects of context in studies of child and youth development. Educational Psychologist, 34, 29-41.

DuRant, R. H., Cadenhead, C., Pendergrast, R. A., Slavens, G., \& Linder, C. W. (1994). Factors associated with the use of violence among urban Black adolescents. American Journal of Public Health, 84, 612-617.

Espelage, D. L., Bosworth, K., \& Simon, T. R. (2000). Examining the social context of bullying behaviors in early adolescence. Journal of Counseling and Development, 78, 326-333.

Farrell, A. D., Danish, S. J., \& Howard, C. W. (1992a). Relationship between drug use and other problem behaviors in urban adolescents. Journal of Consulting and Clinical Psychology, 60, $705-712$.

Flouri, E., \& Buchanan, A. (2003). The role of mother involvement and father involvement in adolescent bullying behavior. Journal of Interpersonal Violence, 18, 634-644.

Galen, B. R., \& Underwood, M. K. (1997). A developmental investigation of social aggression among children. Developmental Psychology, 33, 589-600. doi:10.1037/0012-1649.33.4.589.

Gendron, B. P., Williams, K. R., \& Guerra, N. G. (2011). An analysis of bullying among students within schools: Estimating the effects of individual normative beliefs, self-esteem, and school climate. Journal of School Violence, 10, 150-164.

Gladden, R. M., Vivolo-Kantor, A. M., Hamburger, M. E., \& Lumpkin, C. D. (2013). Bullying surveillance among youths: Uniform definitions for public health and recommended data elements, Version 1.0. Atlanta, GA: National Center for Injury Prevention and Control, Centers for Disease Control and Prevention and U.S. Department of Education.

Hemphill, S. A., Kotevski, A., Tollit, M., Smith, R., Herrenkohl, T. I., Toumbourou, J. W., \& Catalano, R. F. (2012). Longitudinal predictors of cyber and traditional bullying perpetration in Australian Secondary School students. Journal of Adolescent Health. doi:10.1016/j.jadohealth.2011.11.019.

Herrenkohl, T. I., Hill, K. G., Chung, I., Guo, J., Abbott, R. D., \& Hawkins, J. (2003). Protective factors against serious violent behavior in adolescence: A prospective study of aggressive children. Social Work Research, 27(3), 179-191. doi:10.1093/swr/27.3.179

Jencks, C., \& Mayer, S. (1990). The social consequences of growing up in a poor neighborhood. In L. E. Lynn \& M. F. H. McGeary (Eds.), Inner-city poverty in the United States (pp. 111-186). Washington, DC: National Academy Press. 
Jennings, W. G., Maldonado-Molina, M., Reingle, J., \& Komro, K. (2011). A multi-level approach to investigating school-level neighborhood effects on physical aggression among urban Chicago youth. American Journal of Criminal Justice, 36, 392-407.

Jessor, R., Van Den Bos, J., Vanderryn, J., Costa, F. M., \& Turbin, M. S. (1995). Protective factors in adolescent problem behavior: Moderator effects and developmental change. Developmental psychology, 31(6), 923-933.

Jose, P. E., Ryan, N., \& Pryor, J. (2012). Does social connectedness promote a greater sense of well-being in adolescence over time? Journal of Research on Adolescence, 22(2), 235-251. doi:10.1111/j.1532-7795.2012.00783.

Juvonen, J., Graham, S., \& Schuster, M. A. (2003). Bullying among young adolescents: The strong, the weak, and the troubled. Pediatrics, 112, 1231-1237. doi:10.1542/peds.112.6.1231

Karriker-Jaffe, K. J., Foshee, V. A., Ennett, S. T., \& Suchindran, C. (2013). Associations of neighborhood and family factors with trajectories of physical and social aggression during adolescence. Journal of Youth and Adolescence, 42 (6), 861-877. doi:10.1007/s10964-012-9832

Kerpelman, J. L., Eryigit, S., \& Stephens, C. J. (2008). African American adolescents' future education orientation: Associations with self-efficacy, ethnic identity, and perceived parental support. Journal of Youth and Adolescence, 37, 997-1008.

Khamis, V. (2014). Bullying among school-age children in the greater Beirut area: Risk and protective factors. Child Abuse \& Neglect, 39, doi:10.1016/j.chiabu.2014.08.005

Kim, Y. S., Koh, Y., \& Leventhal, B. L. (2004). Prevalence of school bullying in Korean middle school students. Archives of Pediatrics \& Adolescent Medicine, 158, 737-741.

Kokkinos, C. M., \& Kipritsi, E. (2011). The relationship between bullying, victimization, trait emotional intelligence, self-efficacy and empathy among preadolescents. Social Psychology of Education, 15(1), 41-58.

Kretman, S. E., Zimmerman, M. A., Morrel-Samuels, S., \& Hudson, D. (2009). Adolescent violence: Risk, resilience and prevention. In R. J. DiClemente, J. S. Santelli, \& R. A. Crosby (Eds.), Adolescent health: Understanding and preventing risk behaviors (pp. 213-232). San Fransisco: Jossey-Bass.

Lagerspetz, K. M. J., Björkqvist, K., \& Peltonen, T. (1988). Is indirect aggression typical of females? Gender differences in aggressiveness in 11- to 12-year-old children. Aggressive Behavior, 14, 403-414. doi: 10.1002/1098-2337(1988) 14:6<403::AID-AB2480140602>3.0.CO;2-D

Lenzi, M., Vieno, A., Perkins, D. D., Pastore, M., Santinello, M., \& Mazzardis, S. (2012). Perceived neighborhood social resources as determinants of prosocial behavior in early adolescence. American Journal of Community Psychology, 50(1-2), 37-49.

Leventhal, T., \& Brooks-Gunn, J. (2000). The neighborhoods they live in: The effects of neighborhood residence on child and adolescent outcomes. Psychological Bulletin, 126, 309-337.

Loeber, R. (1996). Developmental continuity, change, and pathways in male juvenile problem behaviors and delinquency. In J. D. Hawkins (Ed.), Delinquency and crime: Current theories (pp. 1-27). New York: Cambridge University Press.

Loeber, R., \& Hay, D. (1997). Key issues in the development of aggression and violence from childhood to early adulthood. Annual Review of Psychology, 48, 371-410.

MacDonald, K. (1992). Warmth as a developmental construct: An evolutionary analysis. Child Development, 63, 753-773.

Masten, A., Cutuli, J. J., Herbers, J. E., \& Reed, M. (2002). Resilience in development. In C. R. Snyder \& S. J. Lopez (Eds.), Handbook of positive psychology (pp. 117-131). New York: Oxford University Press.

McCabe, K. M., \& Barnett, D. (2000). The relation between familial factors and the future orientation of urban, African American sixth graders. Journal of Child and Family Studies, 9, 491-508. 
Merrell, K. W., Gueldner, B. A., Ross, S. W., \& Isava, D. M. (2008). How effective are school bullying intervention programs? A meta-analysis of intervention research. School Psychology Quarterly, 23(1), 26-42.

Molnar, B. E., Cerda, M., Roberts, A. L., \& Buka, S. L. (2008). Effects of neighborhood resource on aggressive and delinquent behaviors among urban youths. American Journal of Public Health, 98, 1086-1093.

Multisite Violence Prevention Project. (2004). The multisite violence prevention project: Background and overview. Journal of Preventative Medicine, 26, 3-11.

Nansel, T. R., Overpeck, M., Pilla, R. S., Ruan, J., Simons-Morton, B., \& Scheidt, P. (2001). Bullying behaviors among US youth: Prevalence and association with psychosocial adjustment. Journal of the American Medical Association, 285(16), 2094-2100.

Nurmi, J. (1989a). Planning, movitation, and evaluation in orientation to the future: A latent structure analysis. Scandinavian Journal of Psychology, 30, 64-71.

Nurmi, J. (1989b). Development of orientation to the future during early adolescence: A four-year longitudinal study and two cross-sectional comparisons. International Journal of Psychology, 24, 195-214.

Nurmi, J. (1991). How do adolescents see their future? A review of the development of future orientation and planning. Developmental Review, 11, 1-59.

Nurmi, J. (1993). Adolescent development in an age-graded context: The role of personal beliefs, goals, and strategies in the lacking of developmental tasks and standards. International Journal of Behavioral Development, 16, 169-189.

Nurmi, J., Poole, M. E., \& Seginer, R. (1995). Tracks and transitions: A comparison of adolescent future-oriented goals, explorations, and commitments in Australia, Israel, and Finland. International Journal of Psychology, 30, 355-375.

Nuttin, J. (1964). The future time perspective in human motivation and learning: Proceedings from the 17th International Congress of Psychology. Amsterdam: North-Holland Publishing Co.

Odgers, C. L., Moffitt, T. E., Tach, L. M., Sampson, R. J., Taylor, A., Matthews, C. L., \& Caspi, A. (2009). The protective effects of neighborhood collective efficacy on British children growing up in deprivation: A developmental analysis. Developmental Psychology, 45(4), 942-957. doi:10.1037/a0016162

Olweus, D. (1993). Bully/victim problems among schoolchildren: Long-term consequences and an effective intervention program. In S. Hodgins (Ed.), Mental disorder and crime (pp. 317-349). Thousand Oaks: Sage.

Pendell, S. D. (2002). Affection in interpersonal relationships: Not just "a fond or tender feeling." Communication Yearbook, 26, 70-115.

Reiss, A. J., \& Roth, J. A. (Eds.). (1993). Understanding and preventing violence (Vol. 1). Washington, DC: National Academy.

Romano, E., Tremblay, R. E., Boulerice, B., \& Swisher, R. (2005). Multilevel correlates of childhood physical aggression and prosocial behavior. Journal of Abnormal Child Psychology, 33(5), $565-578$.

Routledge, C., \& Arndt, J. (2005). Time and terror: Managing temporal consciousness and the awareness of mortality. In A. Strathman \& J. Joireman (Eds.), Understanding behavior in the context of time (pp. 59-84). New Jersey: Lawrence Erlbaum.

Sampson, R. J. (2006). Collective efficacy theory: Lessons learned and directions for future inquiry. In F. T. Cullen, J. P. Wright, \& K. R. Blevins (Eds.), Taking stock: The status of criminological theory (Advances in criminology theory: Vol. 15, pp. 149-167). New Brunswick, NJ: Transaction.

Sampson, R. J., \& Raudenbush, S. W. (1999). Systematic social observation of public spaces: A new look at disorder in urban neighborhoods. American Journal of Sociology, 105, 603-651.

Shaw, C. R., \& McKay, H. D. (1942). Juvenile delinquency and urban areas. Chicago: University of Chicago Press. 
Shetgiri, R., Lin, H., \& Flores, G. (2013). Trends in risk and protective factors for child bullying perpetration in the United States. Child Psychiatry and Human Development, 44(1), 89-104. doi:10.1007/s10578-012-0312-3

Smrekar, C. E., \& Bentley, L. (2011). HOPE VI neighborhoods and neighborhood schools: Understanding how revitalized neighborhoods influence school environments. Peabody Journal of Education, 86(4), 416-435. doi:10.1080/0161956X.2011.597272

Snyder, C. R., \& Lopez, S. J. (2005). Handbook of positive psychology. New York: Oxford University Press.

Sobel, M. E. (1982). Asymptotic intervals for indirect effects in structural equation models. In S. Leinhart (Ed.), Sociological methodology (pp. 290-312). San Francisco: Jossey-Bass.

Stassen, K. (2007). Update on bullying: Science forgotten? Developmental Review, 27, 90-126.

Stefanek, E., Strohmeier, D., van de Schoot, R., \& Spiel, C. (2011). Bullying and victimization in ethically diverse schools: Risk and protective factors on the individual and class level. International Journal of Developmental Science, 5(1-2), 73-84.

Stoddard, S. A., Schmidt, C. J., Saulson, R., \& Zimmerman, M. A. (2013). Cumulative risk and promotive factors and physical and relational aggression during early adolescence. Retrieved from https://apha.confex.com/apha/141am/webprogram/Paper292383.html

Stoddard, S. A., McMorris, B., \& Sieving, R. E. (2011). Do social contexts and hope matter in predicting early adolescent violence? American Journal of Community Psychology, 48, 247-56. doi:10.1007/s10464/010/9387/9.

Stoddard, S., Zimmerman, M. A., \& Bauermeister, J. (2011). Thinking about the future as a way to succeed in the present: A longitudinal study of future orientation and violent behaviors among African American youth. American Journal Of Community Psychology, 48(3/4), 238-246. doi:10.1007/s10464-010-9383-0

Trommsdorff, G. (1983). Future orientation and socialization. International Journal of Psychology, $18,381-406$.

Trommsdorff, G., Lamm, H., \& Schmidt, R. W. (1979). A longitudinal study of adolescents' future orientation (time perspective). Journal of Youth and Adolescence, 8, 132-147

Vanfossen, B., Hendricks-Brown, C., Kellam, S., Sokoloff, N., \& Doering, S. (2010). Neighborhood context and the development of aggression in boys and girls. Journal of Community Psychology, 46(3), 329-349.

Veenstra, R., Lindenberg, S., Munniksma, A, \& Dijkstra, J. K. (2010). The complex relation between bullying, victimization, acceptance, and rejection: Giving special attention to status, affection, and sex differences. Child Development, 81(2), 480-486.

Wang, J., Iannotti, R. J., \& Nansel, T. R. (2009). School bullying among adolescents in the United States: Physical, verbal, relational, and cyber. Journal of Adolescent Health, 45, 368-375. doi:10.1016/j.jadohealth.2009.03.021

Williams, J., Fredland, N., Han, H., Campbell, J. C., \& Kub, J. E. (2009). Relational aggression and adverse psychosocial and physical health symptoms among urban adolescents. Public Health Nursing, 26(6), 489-499. doi:10.1111/j.1525-1446.2009.00808.x

Willits, D., Broidy, L., \& Denman, K. (2013). Schools, neighborhood risk factors, and crime. Crime \& Delinquency, 59(2), 292-315.

Wolke, D., Woods, S., Bloomfield, L., \& Karstadt, L. (2001). Bullying involvement in primary school and common health problems. Archives of Disease in Childhood, 85, 197-201. doi:10.1136/adc.85.3.197

Wyman, P. A., Cowen, E. L., Work, W. C., \& Kerley, J. H. (1993). The role of children's future expectations in self-system functioning and adjustment to life stress: A prospective study of urban at-risk youth. Development and Psychopathology, 5(4), 649-661. 
Zimmerman, M. A., Bingenheimer, J. B., \& Notaro, P. C. (2002). Natural mentors and adolescent resiliency: A study with urban youth. American Journal of Community Psychology, 30 (2), 221243.

Zimmerman, F. J., Glew, G. M., Christakis, D. A., \& Katon, W. (2005). Early cognitive stimulation, emotional support, and television watching as predictors of subsequent bullying among gradeschool children. Archives of Pediatrics \& Adolescent Medicine, 159, 384-388. 